\title{
Optimisation procedure for pipe-sizing with break-repair and replacement economics
}

\author{
TR Neelakantan ${ }^{1}$, CR Suribabu ${ }^{2 *}$ and Srinivasa Lingireddy ${ }^{3}$ \\ ${ }^{1}$ School of Civil Engineering, SASTRA University, Thanjavur, TN 613402, India \\ ${ }^{2}$ School of Civil Engineering, SASTRA University, Thanjavur, TN 613402, India \\ ${ }^{3}$ Department of Civil Engineering, University of Kentucky, Lexington, KY 40504, USA
}

\begin{abstract}
The importance of incorporating break-repair costs and pipe-replacement costs in optimal design of a water distribution network is highlighted and demonstrated with a hypothetical network. Deterioration due to ageing of pipes requires expensive maintenance and causes inconvenience. The number of breaks generally increases exponentially with pipe age and smalldiameter pipes are more likely to break than large-diameter pipes. After a certain age, it would be more cost-effective to replace the pipes than to repair them. The optimisation models which do not consider the maintenance costs tend to result in smaller pipe sizes. The proposed model incorporates both the repair cost and the replacement cost in addition to initial cost. The proposed model is demonstrated by applying it to a 2-loop network. Incorporating pipe-break and replacement economics into optimisation leads to slightly larger diameter pipes. The analysis also reveals that consideration of repair/replacement is essential if the pipe breaks cause high economic impact, the pipe-break growth rate increases fast and discount rate is low. For the example network considered, for a typical set of values, the cost benefit is as much as $12.92 \%$. For cases with low breakage rates, incorporating repair/replacement has been found to make no practical difference. The results show that considering pipe break and pipe replacement in optimisation is important as this could save considerable amounts of money over the lifetime.
\end{abstract}

Keywords: water distribution network, pipe-break analysis, optimisation, network design, economics

\section{Introduction}

Water distribution systems are subject to deterioration with age. The design procedures of distribution systems should consider the future scenarios too. Pipe breaks are one of the important parameters to be considered in distribution system design. When a pipe breaks, it has either to be repaired or replaced. The breaks are not only associated with the direct costs to repair but also the indirect costs that are due to the inconveniences caused at widely varying levels. Water pipe breaks result not only in disrupting service but also in significant loss of water, which otherwise could have been sold to the consumer (Sinske and Zietsman, 2004). In addition to this it may disrupt the traffic and the working of a water-intensive industry. There may be outbreaks of diseases and sometimes fire fighting could be delayed. Thus, pipe-break analysis needs to be considered during the design of the water distribution system, to be realistic. A pipe can break due to many reasons, including age of pipe, material and quality of pipe, surrounding environment of the pipe like soil corrosivity, external load on pipe, quality of workmanship, water-hammer pressures, etc. With all other conditions remaining the same, the number of breaks increases with age. Thus, over a planning horizon or period of analysis of 50 years or so, the number of breaks gradually increases.

Generally, small-diameter pipes are more liable to breaks than large-diameter pipes (Kettler and Goulter, 1985). An initial cost-optimisation model that does not consider the pipe breaks during the lifetime may result in pipes of smaller diameter. This

\footnotetext{
* To whom all correspondence should be addressed.

용 +91-04362-264101; fax: +91-04362-264120;

e-mail: suribabu@civil.sastra.edu

Received 27 March 2007; accepted in revised form 28 November 2007.
}

might prove to be less optimal over a long run, as the distribution system tends to experience more breaks when compared to a system with slightly larger diameter pipes. Even though the initial cost is more, larger diameter pipes may be more economical than smaller diameter pipes when life- cycle costs are considered. Therefore a critical analysis is required to decide on the appropriate size of the pipe which ultimately leads to economical design in longer run. To analyse for long design periods, the time variations of break rates of different pipe sizes have to be known. Further the interest rate (discount rate) on finances also plays an important role. To choose a design from different alternatives, the 'present value method' may be used.

Minimising pipe cost is often reported as the objective in the literature that deals with water distribution design. However, repairing pipe breaks and related inconveniences also significantly add to the cost. These factors are not dealt with often. In this paper, it is shown that there is an improvement by incorporating installation cost and repair and replacement economics into an optimisation framework. The objectives of this study were to develop an optimisation model that optimises the total cost of installation of a water distribution system and maintenance of the system for its service life (say 50 years), and to demonstrate the advantages of this model over the model that does not include maintenance cost in optimisation.

\section{Review of optimisation studies}

Generally, optimisation models have been used for one of the following purposes:

- Pipe cost minimisation

- Strengthening of an existing network to enhance its capacity

- Expansion of a distribution network to cover new service 
areas (stage-wise planning)

- Reliability based design of water distribution networks

- Calibration of network parameters

- Optimisation of system operations like minimising energy, scheduling of booster disinfection, and water quality monitoring.

Researchers have been investigating costs of effective water distribution networks with various approaches such as linear, nonlinear, dynamic and mixed integer programming. Optimisation models have been formulated and solved for the design of water distribution systems since the 1970s. Goulter (1992) provided an extensive review of the optimisation models applied to water distribution design. Recently many evolutionary and heuristic optimisation models (simulated annealing, genetic algorithm, ant colony algorithm, and shuffled frog leap algorithm) have been applied to the pipe network optimisation problem (Simpson et al, 1994; Savic and Walters, 1997; Cunha and Sousa, 1999; Maier et al, 2003; Eusuff and Lansey, 2003). For upgrading and enhancing water distribution networks, Boulos and Wood (1990) proposed a method for determining different parameters explicitly. For use in upgrading existing networks in order to sustain any single component failure, Ormsbee and Kessler (1990) suggested a linear programmingbased method, and Lingireddy et al. (2000) presented a genetic algorithm method. Lai and Schaake (1969) presented a methodology based on linear and dynamic programming for optimal expansion of the New York City water supply problem; subsequently many others have also applied different optimisation techniques for optimal expansion of the same network. Stagewise planning was demonstrated by Martin (1990) through a dynamic programming model, minimising the cost of initial construction and subsequent capacity expansion. Dandy and Engelhardt (2001) used a genetic algorithm to find an optimal schedule for the replacement of water supply pipes. Luong and Nagarur (2005) proposed a mathematical model to find an optimal fund allocation for better maintenance of distribution network and decision on repair or replacing the components in case of failure state. Dandy and Engelhardt (2006) developed trade-off curves between cost and reliability for pipe replacement decisions for the water distribution network of the northern suburbs of Adelaide, Australia. Jayaram and Srinivasan (2008) proposed a multi-objective formulation with 'minimisation of life-cycle cost' and 'maximisation of performance' as objectives for the optimal design and rehabilitation of a water distribution network. The life-cycle cost includes the initial cost of pipes, the cost of replacing old pipes with new ones, the cost of cleaning and lining existing pipes, the expected repair cost for pipe breaks and the salvage value of the pipes that are replaced.

Kettler and Goulter (1983), Goulter and Coals (1986), Su et al. (1987), Bao and Mays (1990), Fujiwara and Tung (1991), Cullinane et al. (1992) and Prasad and Park (2004) have developed reliability-based optimisation models. Recently, Balla and Lingireddy (2000), Vitkovsky et al. (2000), Lansey et al. (2001), Lingireddy and Ormsbee (2002), Mallick et al. (2002) and Kapelan et al. (2003) have worked on the roughness calibration of a water distribution network. Investigations on the booster facility location and injection scheduling problem in water distribution networks is dealt with by Boccelli et al. (1998), Tryby et al. (2002) and Prasad et al (2004). Of all the optimisation methods, genetic algorithm-based methods appear to be promising, since they are able to handle discrete decision variables (pipe sizes) with ease and produce a set of promising solutions.

\section{Review of pipe-break studies}

Goulter and Bouchart (1990) presented methodology for incorporating reliability measure in least cost optimal design of water distribution network in which pipe-break rates for diameters ranging between $25 \mathrm{~mm}$ and $610 \mathrm{~mm}$ are considered. They assumed an average break rate of 1.55 breaks $/ \mathrm{yr} \cdot \mathrm{km}$ for a $25 \mathrm{~mm}$ diameter pipe. For the diameters between $50 \mathrm{~mm}$ and $305 \mathrm{~mm}$, they have taken the average break rate from the data collected for the city of Winnipeg, Canada during 1975 to 1980 (Kettler and Goulter, 1985). The pipes in the Winnipeg water distribution system were installed between 1950 and 1959. For diameters larger than $305 \mathrm{~mm}$, they assumed average break rates. For 610 $\mathrm{mm}$, the assumed break rate was 0.026 breaks $/ \mathrm{yr} \cdot \mathrm{km}$. Kettler and Goulter (1983), Goulter and Coals (1986), Fujiwara and DeSilva (1990) and Fujiwara and Tung (1991) assumed expected break rates ranging between 1.36 and 0.05 breaks $/ \mathrm{yr} \cdot \mathrm{km}$ for diameters ranging between 100 and $350 \mathrm{~mm}$. Gupta and Bhave (1994) assumed break rates ranging between 1.04 and 0.05 breaks/ $\mathrm{yr} \cdot \mathrm{km}$ for the diameters ranging between 150 and $400 \mathrm{~mm}$.

The variation of number of breaks with respect to time will be more useful for analyses over long periods. Shamir and Howard (1979) proposed two expressions, a linear and an exponential one for break rates, as a function of time, that have the following forms:

$$
\begin{aligned}
& N(t)=N\left(t_{0}\right)+A\left(t-t_{0}\right) \\
& N(t)=N\left(t_{0}\right) \exp \left(A\left(t-t_{0}\right)\right)
\end{aligned}
$$

where:

$N(t)$ is the number of breaks per unit length per year at time $t$

$N\left(t_{0}\right)$ is the number of breaks per year per unit length at time $t=t_{0}$

$A$ is the growth-rate coefficient

Typical values of $N\left(t_{0}\right)$ and $A$ are presented in Table 1 . Shamir and Howard (1979) further derived an equation that provided time of replacement of pipes based on break rate and interest rate. The exponential expression (Eq. (2)) was reported to give better results than the linear expression (Shamir and Howard, 1979; Walski and Pelliccia, 1982; Kleiner and Rajani, 1999). Pipes can be grouped into classes with the same characteristics (type of material, diameter, installation periods, etc.) and parameter values estimated for each of these classes (Kleiner and Rajani, 1999). Goulter and Kazemi (1988) and Goulter et al. (1993) proposed a non-homogeneous Poisson distribution model to predict the probability of subsequent breaks provided first break had already occurred. Male et al. (1990) used a net present value analysis to investigate the best replacement policy or the number of bursts that should be allowed to occur before a replacement was necessary. A semi-Markovian model was developed by Li and Haimes (1992a) to capture the dynamic evolution of the failure mode of a deteriorating main pipe, thus facilitating the determination of the optimal replacement/repair decision at various deteriorating stages. A water distribution system often consists of a large number of components. However, funds are, in general, not available to completely update/upgrade the deteriorating water distribution system's components. Li and Haimes (1992b) proposed a multilevel approach for water distribution systems that maximises the performance of the overall system under a given budget constraint. Loganathan et al (2002) developed an economical sustainable threshold break rate equation. The equation for threshold break rate considers the pipe diameter and the discount rate, which provides the critical break 
rate for optimal replacement of pipe and failure intensity. More recently, Mailhot et al. (2003) derived closedform expressions for probability density functions of occurrence of pipe breaks as well as expressions for the time evolution of the average number of pipe breaks per unit time. Sinske and Zietsman (2004) developed a spatial decision support system (SDSS)

for pipe-break susceptibility analysis, which helps public works administrator to model the complex pipe-break phenomena in a municipal water distribution system in order to identify pipes susceptible to breaking.

Comparison of the equivalent present value of competing alternative designs allows choosing the most desirable design on the basis of economics. Present value analysis requires the conversion of all cash flows to a common point in time, the present or the start time. All future cash flows are discounted back to the present using the interest (discount) rate. Discount rates or interest rates used in economic analysis of water distribution networks usually range between 2 and $12 \%$, depending upon the funding agency. Table 1 provides the discount rates used in the literature. Although studies on break analysis and pipe replacement scheduling have been conducted by many, no study seems to include pipe-break and replacement economics in the optimal design of water distribution.

\section{Model formulation}

The following definitions are used in this paper. Installation cost means the cost of pipes plus the cost of laying the pipes that includes the costs for excavation, preparing foundation, placing the pipes with sleeves, filling, repaving, crew, equipment and overhead. Repair cost means the cost to repair a break. Break cost means the cost to repair a break plus the costs on claims for damages and other inconveniences. Maintenance cost is the total of break costs and replacement costs.

The objective of the model is to minimise the total cost that includes the installation cost and maintenance cost over a period of analysis. The installation cost is the cost to be spent at the beginning whereas the maintenance cost is spread over the analysis period. All the costs are brought to the beginning period using the present worth method so as to compare different designs and select the best. After a certain period of time, pipes may break often and instead of being repaired they may have to be replaced. Thus two scenarios are considered. In the $1^{\text {st }}$ scenario, the pipes are not replaced for the entire period of analysis. In the $2^{\text {nd }}$ scenario, pipes are replaced at optimal times.

A combined simulation-optimisation model is developed. The optimisation model is the outer driver model and the simulation model is the core. A genetic algorithm is used for optimisation. United States Environmental Protection Agency (USEPA) developed the freeware analysis software called EPANET (Rossman, 2000) and this is used as the simulation model. A computer code is written for genetic algorithm in C programming language and the simulation model EPANET is linked to the optimiser, through the EPANET Toolkit.

The optimisation is performed using a single objective genetic algorithm. The objective function for the first scenario in which the replacement is not considered, can be written as follows:

$$
\text { Min } C=I C+B C
$$

\section{TABLE 1} \begin{tabular}{l} 
ed in the literature for break rates and discount rate \\
\hline Break growth
\end{tabular} rate $A$ (per year) $\quad N\left(t_{0}\right)$ (break/yr $\left.\cdot \mathbf{k m}\right) \quad$ (per year)

\begin{tabular}{c|c|c|}
\hline $0.01-0.15$ & $0.033-0.656$ & $0.05-0.15$ \\
\hline
\end{tabular}

$0.0207,0.0137$

0.0137

\begin{tabular}{l|r}
$0.033-0.656$ & $0.05-0.15$ \\
\hline $0.088,0.140$ & 0.07
\end{tabular}

$0.01-0.19$

$0.003-0.134$

where:

$C$ is a cost function

$I C$ is the installation cost (including pipe cost)

$B C$ is the present worth value of break costs during the analysis period

The installation cost $I C$ can be represented as follows:

$$
I C=\sum_{j=1}^{n} I_{d(j)} \cdot l_{j}
$$

where:

$n$ is the number of links in the network

$d(j)$ is the diameter selected for link $j$

$I_{d(j)}$ is the installation cost per unit length for the link $j$ with diameter $d(j)$

$l_{j}$ is the length of link $j$

The present worth value of break cost $B C$ can be represented as follows:

$$
B C=\sum_{r=1}^{y}\left[\frac{1}{(1+i)^{r}} \sum_{j=1}^{n} N_{d(j)} \cdot \exp (A \cdot r) \cdot B_{d(j)} \cdot D \cdot l_{j}\right]
$$

where:

$r$ is the period of analysis in years

$y$ is the maximum period of analysis in years

$i$ is the discount rate (per year)

$N_{d(j)}$ is the break rate (break/year/unit length) for diameter

$d(j)$ at the beginning of the analysis

$A$ is a break growth rate coefficient (per year)

$B_{d(j)}$ is the repair cost per break ( $\$ /$ break) in pipe of diameter $d(j)$

$D$ is the damage and inconvenience cost multiplier.

$N_{d(j)} \cdot \exp (A \cdot r)$ of Eq. (5) represents the exponential equation given by Shamir and Howard (1979) to describe the break rate as a function of time (Eq. (2)). $1 /(1+i)^{r}$ of Eq. (5) is used to convert the break cost to present value. The multiplier factor $D$ is introduced as the claims for damage and other inconveniences caused by breaks can be significant in comparison to the cost of actually repairing a break (Walski and Pelliccia, 1982). When $D$ is assumed to be equal to 1 , the damage and inconvenience cost is ignored.

The objective function needs to be minimised subject to a set of implicit constraints and a set of explicit bound constraints. The explicit constraints are used to set limits on explicit decision variables (pipe diameters) of the design problem. A set of discrete pipe diameters are provided and the model can use only those diameters. The implicit system constraints include nodal conservation of mass and conservation of energy. Nodal conservation of mass requires that the sum of flows into or out of any junction minus any external demand must equal zero. Energy conservation requires that the sum of the head losses over any loop minus any energy added by a pump, minus the difference in grade between any two fixed grade nodes equals zero. 
EPANET solver satisfies the continuity equation at all times; however, pressures need to be checked. In the present model, minimum pressure requirement at each demand node can be specified. Only those solutions which do not violate the pressure constraints are considered feasible solutions. For other solutions that violate pressure constraints, a heavy penalty $\left(\$ 10^{20}\right)$ is added to the objective function for each violation. The penalty is set so high that the solutions violating pressure constraints could not be selected as the optimal solution.

The following assumptions are made in the formulation and demonstration:

- The optimisation considers only the pipes and other components of the system like the pumps, overhead tanks, etc. are not considered.

- Water quality is assumed not affected by optimisation.

- The inconvenience and other cost multiplier D is assumed constant throughout the system and throughout the analysis period while in practice in may vary in space and time.

- The exponential break growth equation is assumed valid. However, if a better equation is available, that can be incorporated in the optimisation model.

- A constant Hazen-Williams roughness coefficient is used

- Though stage-by-stage construction of network and rehabilitation of pipes can be incorporated in the proposed model, they have not been considered in the present study.

\section{Demonstration}

The water distribution network shown in Fig. 1 is used for demonstration. This network was first used by Alperovits and Shamir (1977) for optimal design and subsequently several researchers used the same network for optimisation studies. The network consists of 8 links, 6 demand nodes, and 1 reservoir (Node 1). The node details of this network are given in Table 2. The minimum required pressure at all demand nodes is $30 \mathrm{~m}$. Each link is $1000 \mathrm{~m}$ long. Alperovits and Shamir (1977) and subsequently many others used a constant Hazen-Williams coefficient of 130 for all pipes. As the analysis is made over a period of 50 years in this study, a smaller Hazen-Williams coefficient, 100, is used for all pipes.

Alperovits and Shamir (1977) also gave cost details of pipes. It is to be noted that they provided only arbitrary cost units but not cost itself. These cost units are not directly and linearly proportional to the real cost of the pipes. Compared to the pipe cost, the laying cost is also significant. Hence, it may be useful to practising engineers, if the totals of pipe cost and laying cost are used in the optimisation models. Walski and Pelliccia (1982) included ductile iron-pipe installation costs. They also estimated the cost to repair a break considering components like the costs for crew, equipment, sleeve, repaving and overheads. The cost data provided by them are more realistic though there may be some variation from place to place. Since these costs are more realistic values, they are used in this study. Costs are assumed for some pipes $(25 \mathrm{~mm}, 50 \mathrm{~mm}, 75 \mathrm{~mm}, 100 \mathrm{~mm}$ and $550 \mathrm{~mm})$ for which Walski and Pelliccia (1982) did not provide data. The cost data used in this study are presented in Table 3. The pipe costs and the installation costs provided are based on estimates of laying works for long lengths. The pipe-break rates (break/ $\mathrm{yr} \cdot \mathrm{km}$ ) are used in many studies in the literature, but most of them are assumed values. Moreover, the values available in the literature are mostly average break rates. Goulter and Bouchart (1990) provided average break rate values (time averaged) of a real system for a few pipe diameters. In the present study, break rates for different diameter pipes at the beginning of analysis

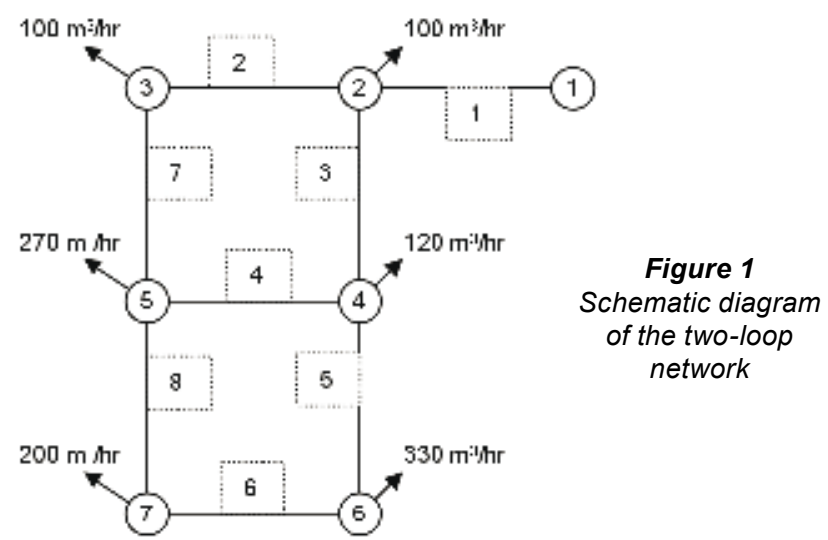

Legend (5) Node Nurnber 6 -ink Number

\begin{tabular}{|c|c|c|c|}
\hline \multicolumn{5}{|c|}{ TABLE 2 } \\
\hline Node details of two-loop network \\
\hline & $\begin{array}{c}\text { Elevation } \\
(\mathbf{m})\end{array}$ & $\begin{array}{c}\text { Min. pressure } \\
(\mathbf{m})\end{array}$ & $\begin{array}{c}\text { Demand } \\
\left(\mathbf{m}^{\mathbf{3}} \mathbf{h} \mathbf{h}\right.\end{array}$ \\
\hline 1 & 210 & - & -1120 \\
\hline 2 & 150 & 30 & 100 \\
\hline 3 & 160 & 30 & 100 \\
\hline 4 & 155 & 30 & 120 \\
\hline 5 & 150 & 30 & 270 \\
\hline 6 & 165 & 30 & 330 \\
\hline 7 & 160 & 30 & 200 \\
\hline
\end{tabular}

\begin{tabular}{|c|c|c|c|c|}
\hline \multicolumn{5}{|c|}{$\begin{array}{c}\text { TABLE } 3 \\
\text { Cost and break details of the pipes }\end{array}$} \\
\hline $\begin{array}{c}\text { Diameter } \\
(\mathrm{mm})\end{array}$ & $\begin{array}{l}\text { Diameter } \\
\text { notation }\end{array}$ & $\begin{array}{c}\text { Pipe and } \\
\text { installa- } \\
\text { tion cost } \\
(\$ / \mathrm{m})\end{array}$ & $\begin{array}{c}\text { Cost to } \\
\text { repair a } \\
\text { break } \\
\text { (\$/break) }\end{array}$ & $\begin{array}{c}\text { No. of breaks } \\
\text { per year per } \\
\text { km at the } \\
\text { beginning } \\
\text { (break/yr.km) }\end{array}$ \\
\hline 25 & E & 52 & 505 & 1.30 \\
\hline 50 & $\mathrm{~F}$ & 55 & 510 & 1.05 \\
\hline 75 & $\mathrm{G}$ & 57 & 530 & 0.81 \\
\hline 100 & $\mathrm{H}$ & 62 & 572 & 0.58 \\
\hline 150 & $\mathrm{~K}$ & 68 & 626 & 0.41 \\
\hline 200 & $\mathrm{~L}$ & 87 & 668 & 0.25 \\
\hline 250 & $\mathrm{M}$ & 105 & 713 & 0.15 \\
\hline 300 & $\mathrm{~N}$ & 121 & 799 & 0.10 \\
\hline 350 & $\mathrm{P}$ & 129 & 960 & 0.08 \\
\hline 400 & $\mathrm{Q}$ & 153 & 1008 & 0.06 \\
\hline 450 & $\mathrm{R}$ & 204 & 1039 & 0.05 \\
\hline 500 & $\mathrm{~S}$ & 260 & 1127 & 0.04 \\
\hline 550 & $\mathrm{~T}$ & 300 & 1250 & 0.03 \\
\hline 600 & $\mathrm{U}$ & 330 & 1409 & 0.02 \\
\hline
\end{tabular}

are required. Reasonable values are assumed and are presented in Table 3. These values are close to the values presented in the literature. In this study, two discount rates $(i), 4 \%$ and $10 \%$ per year, two break growth rate coefficients $(A), 0.01$ and 0.07 per year and three damage and other cost multipliers $(D), 0,1.5$ and 2.5 are used. It is to be noted that when $D=0$, it indicates that $B C=0$ (refer Eq. (5)) and thus the optimisation is for pipe and installation costs only. In other words, when $D$ is set to zero, the break economics are ignored. 


\section{Results of optimisation without pipe replacement}

A genetic algorithm-based optimisation model was used. The optimum results obtained took about 5 to $10 \mathrm{~min}$ of computer time in Pentium IV personal computer. The GA was run using a population size of 1000 and permitted to maximum generations of 1000 . Two runs are generally considered. The cross-over probability and mutation probability were fixed as 0.8 and 0.03 respectively. To present the results conveniently, alphabet letters are used to represent the diameters. The alphabet $\mathrm{E}$ represents $25 \mathrm{~mm}$, F represents $50 \mathrm{~mm}$ and so on. The alphabet notations for different diameters are presented in Table 3, Column 2. The optimisation results are presented in Table 4. Column 5 of Table 4 with title 'Optimal diameter set' provides the optimal diameters found by the genetic algorithm-based optimisation model. The 8 alphabet letters represent 8 diameters for Links 1 through 8 in sequence.

When the initial cost (pipe and installation cost) alone is considered $(D=0)$, the minimum initial cost obtained is $\$ 1.102$ $\mathrm{m}$. Four different configurations with this cost are presented in Table 4 (the rows where $D$ is 0 ). Even though there are four different configurations, they contain $350 \mathrm{~mm}$ pipes for three links, $400 \mathrm{~mm}$ diameter pipes for two links and $25 \mathrm{~mm}, 75 \mathrm{~mm}$ and 550 $\mathrm{mm}$ pipes for one link each. Cases $4 \mathrm{~B}$ and $4 \mathrm{D}$ also produce an initial cost of $\$ 1.102 \mathrm{~m}$. for which $D=1.5, A=0.01$ and $i=10 \%$. In all other cases, the initial cost is more than $\$ 1.102 \mathrm{~m}$. This shows that when break economics is considered in optimisation, generally larger pipes are selected. When breaks are considered in optimisation, $25 \mathrm{~mm}$ pipe is not selected except for Case 4B. When breaks are not considered in optimisation, a $25 \mathrm{~mm}$ pipe is selected in all four configurations (Cases $4 \mathrm{I}, 4 \mathrm{~J}, 4 \mathrm{~K}$ and $4 \mathrm{~L}$ ). The difference in initial cost is maximum in Case $4 \mathrm{G}$, where the initial cost is $\$ 1.179 \mathrm{~m}$. which is higher by $\$ 0.077 \mathrm{~m}$.

The last column of Table 4 provides the total cost which is the total of initial cost and present value of maintenance costs over a period of 50 years. One might like to establish how much the total cost will be when the optimal diameter set of one of Cases $4 \mathrm{I}, 4 \mathrm{~J}, 4 \mathrm{~K}$ or $4 \mathrm{~L}$ is used. The results of optimal diameter sets and diameter set of Case 4I are compared and presented in Table 5. Among the cases considered the maximum benefit (or maximum loss while using Case 4I) while considering the break rate into optimisation works to be $12.92 \%$ of the cost. This is obtained when $D=2.5, A=0.07$ and $i=4 \%$. In other

\begin{tabular}{|c|c|c|c|c|c|c|}
\hline \multicolumn{7}{|c|}{$\begin{array}{c}\text { TABLE } 4 \\
\text { Optimal results without replacement of pipes }\end{array}$} \\
\hline Case & \begin{tabular}{|c|} 
Damage \\
and other \\
cost \\
multiplier \\
$D$
\end{tabular} & \begin{tabular}{|c|} 
Break \\
growth \\
rate coef- \\
ficient \\
$A(1 / y r)$
\end{tabular} & $\begin{array}{l}\text { Discount } \\
\text { rate } i \\
(\% / y r)\end{array}$ & $\begin{array}{c}\text { Optimal } \\
\text { diameter set }\end{array}$ & \begin{tabular}{|c|} 
Initial \\
cost \\
$(1000 \$)$
\end{tabular} & $\begin{array}{c}\text { Total cost } \\
\text { for } 50 \\
\text { years } \\
\left(\begin{array}{ll}1 & 000\end{array}\right)\end{array}$ \\
\hline $4 \mathrm{~A}$ & 1.5 & 0.01 & 4 & SQQK-QHPP & 1107 & 1144.6 \\
\hline $4 \mathrm{~B}$ & 1.5 & 0.01 & 10 & TQPG-QEPP & 1102 & 1126.5 \\
\hline $4 \mathrm{C}$ & 1.5 & 0.07 & 4 & SQQK-QKPP & 1113 & 1274.8 \\
\hline $4 \mathrm{D}$ & 1.5 & 0.07 & 10 & SQQG-QKPP & 1102 & 1146.8 \\
\hline $4 \mathrm{E}$ & 2.5 & 0.01 & 4 & TPQL-PHPP & 1118 & 1176.5 \\
\hline $4 \mathrm{~F}$ & 2.5 & 0.01 & 10 & TPQL-PGPP & 1113 & 1140.7 \\
\hline $4 \mathrm{G}$ & 2.5 & 0.07 & 4 & TPQM-QMPM & 1179 & 1370.1 \\
\hline $4 \mathrm{H}$ & 2.5 & 0.07 & 10 & SQQH-QKPP & 1107 & 1174.8 \\
\hline $4 \mathrm{I}$ & 0 & - & - & TQQE-PGPP & 1102 & - \\
\hline $4 \mathrm{~J}$ & 0 & - & - & TQPG-QEPP & 1102 & - \\
\hline $4 \mathrm{~K}$ & 0 & - & - & TQPE-QGPP & 1102 & - \\
\hline $4 \mathrm{~L}$ & 0 & - & - & TQPG-QEPP & 1102 & - \\
\hline
\end{tabular}

words, when $D$ is high, $A$ is high and $i$ is low, the break economics based optimisation model results significantly different total cost compared to the total cost obtained from a simple optimisation model that does not consider breaks.

However, when $D=1.5, A=0.01$ and $i=10 \%$ there is no benefit in considering the break rates in optimisation. In this particular case, even though the break rates are considered, the optimal set of diameters found is the same as the diameter set found without considering the break rates in the optimisation model. In this particular case, $D$ is small, $A$ is small and $i$ is high.

When the break growth rate $A$ is 0.01 , the number of breaks per year per $\mathrm{km}$ doubles in 69.3 years. When the break growth rate $A$ is 0.07 , the number of breaks per year per km doubles in 9.9 years. The increase in break rates with respect to age is presented in Figs. 2 and 3 respectively for $A=0.01$ and $A=0.07$. The optimum results presented in Table 4 show that keeping $D$ and $i$ constant, the increase in $A$ increases the total cost. A smaller discount rate produces higher present worth total cost. The importance of discount rate increases when the $D$ and $A$ values are high. When $D$ and $A$ are high, discount rate results in more differences in total cost. A high discount rate $i$, small $D$ and small $A$ may produce a result that is close to a cost obtained with minimisation of initial cost alone.

\section{Optimisation results with pipe replacement}

If a pipe is replaced after $t$ number of years, $t$ should be such that the money spent on maintenance for $t$ years and the replacement cost together (present worth) should be minimal. In other words, the optimal timing for replacement is that year for which the total present worth of all maintenance costs and replacement cost is minimal. Using the exponential break-rate equation Eq. (2), Shamir and Howard (1979) formulated an expression for total of repair cost and replacement cost. By differentiating this expression with respect to time and equating to zero $\left(\frac{\partial C}{\partial t}=0\right)$, provides optimal timing of replacement of pipes. According to Shamir and Howard (1979) optimal timing of replacement of pipes $t$ can be written as follows:

$$
t=\frac{1}{A} \ln \left[\frac{\ln (1+i) \cdot C_{r}}{N\left(t_{0}\right) \cdot C_{b}}\right]
$$

where:

$t$ is the optimal year in which a pipe needs to be replaced

$C_{r}$ is the cost of replacement per unit length, say one $\mathrm{km}$

$C_{b}$ is the break cost

$N\left(t_{\theta}\right)$ is the break rate (breaks/yr.km) at the start of analysis.

In this study, $C_{r}$ is taken as cost of pipe and installation (given in Table 3) multiplied by $D$. Similarly $C_{b}$ is the cost to repair a break (given in Table 3 ) multiplied by $D$. Based on this equation the optimal years of replacement are calculated and presented in Table 6 . According to Table 6, in the case of $A=0.01$, all the pipes are to be replaced well after the period of analysis of 50 years. However, when $A=0.07$, the optimal replacement time is within the period of analysis for smaller pipes. Thus another optimisation model was developed to incorporate the pipe replacement at the specified years. In the new 


\begin{tabular}{|c|c|c|c|c|c|}
\hline \multicolumn{6}{|c|}{ TABLE 5 } \\
Comparison of results with and without pipe-break consideration (no pipe replacement)
\end{tabular}

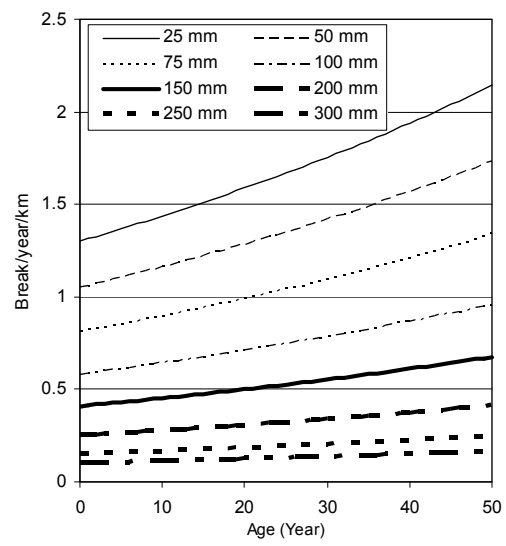

Figure 2a

Break rate variation with age for $A=0.01$

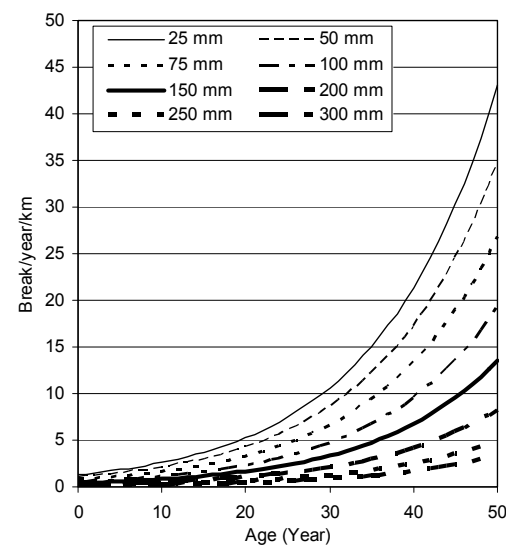

Figure 3a

Break rate variation with age for $A=0.07$

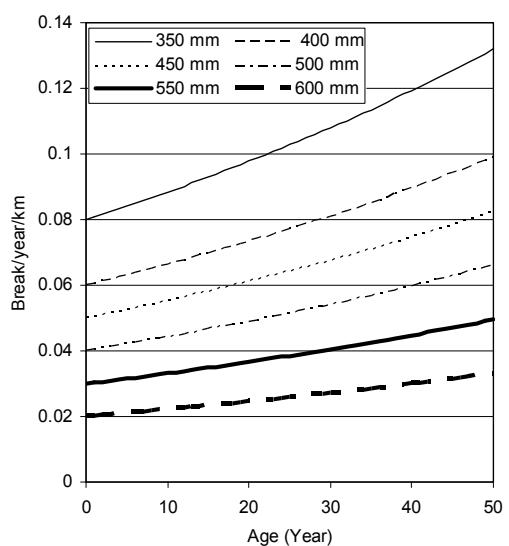

Figure $2 b$

Break rate variation with age for $A=0.01$

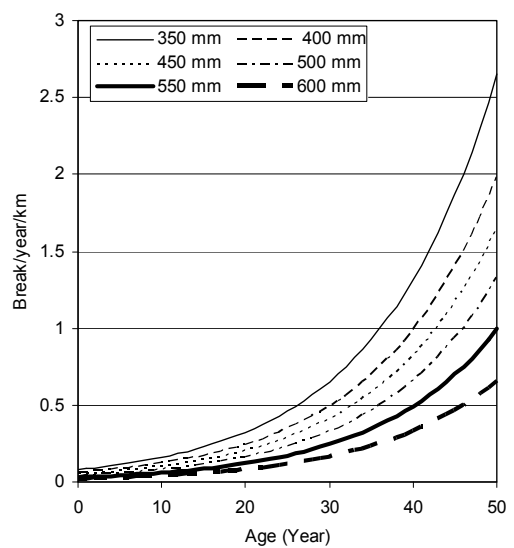

Figure $3 b$

Break rate variation with age for $A=0.07$

7C and 7D respectively. In the $3^{\text {rd }}$ case, the pipes selected did not require to be replaced within 50 years. The results in Table 7 shows that in all the cases except $7 \mathrm{C}$, the total cost obtained by optimisation with pipe replacement is more than the cost obtained with the optimisation without pipe replacement. This is true as the analysis period is not an integral multiple of replacement year and pipe replacement requires relatively large amounts of money. If a pipe is replaced in the $46^{\text {th }}$ year, the benefits of replacing the pipe will not be reflected in the $50^{\text {th }}$ year itself (just 4 years after replacement). For the 4 cases presented in Table 7, the variations of the present worth of maintenance cost with age are shown in Fig. 4. Variation of maintenance cost for a single link $(150 \mathrm{~mm})$ is shown in Fig. 5 in which $i$ is taken as 0.04 and $A$ is taken as 0.07 . The link is replaced at the age of 33 years and the replacement costs (present worth) $\$ 27958$. At the age of 33, the maintenance cost is raised by $\$ 27958$ (present worth) when replacement is considered. The benefit of replacement can be realised at the age of 54 and later during which the cumulative maintenance cost with replacement is less than the cumulative maintenance cost without replacement.

\section{Summary and conclusions}

This paper proposes a methodology for the design of water distribution networks incorporating the pipe-break and the replacement cost economics. The proposed model is an improvement on simple pipe-cost optimisation. Consideration of the break cost and replacement cost in

optimisation model, pipe replacement years are taken from Table 6. For example, if a link is formed with $25 \mathrm{~mm}$ pipe and if $i=0.04$ and $A=0.07$, then the break rates are calculated from the $1^{\text {st }}$ to the $16^{\text {th }}$ year and then the pipe is replaced. The replacement cost is attached to the $16^{\text {th }}$ year. For the next 16 years (from $17^{\text {th }}$ to $32^{\text {nd }}$ year), the break rates are repeated as of the $1^{\text {st }}$ to the $16^{\text {th }}$ year, and the pipe is replaced in the $32^{\text {nd }}$ year. These steps are repeated till the end of the analysis period. For a $25 \mathrm{~mm}$ pipe, the replacement cost is taken as $\$ 52 / \mathrm{m}$ (refer Table 3) multiplied by $D$.

Cases, 4C, 4D, 4G and 4H are analyzed with pipe replacement and the results are presented in Table 7 as Cases 7A, 7B, optimisation results in different optimal sets of pipe diameters. The demonstration example shows the importance of considering the break cost and replacement costs in optimisation. The optimal diameters depend on the break growth rate, initial break rate, inconvenience and inconvenience cost multiplier and discount rates.

The demonstration of the new model with a 2-loop network reveals that the optimisation leads to slightly larger diameter pipes. If the inconvenience cost, break growth rate and discount rate are all unfavourable, the simple optimisation without considering the pipe-break and replacement economic may result in a poor design. Network design with breaks causing high economic 


\begin{tabular}{|c|c|c|c|c|}
\hline \multicolumn{5}{|c|}{ TABLE 6 } \\
\hline \multirow{2}{*}{$\begin{array}{c}\text { Oiameter } \\
(\mathbf{m m})\end{array}$} & \multicolumn{3}{|c|}{ Optimal replacement age (year) } \\
\cline { 2 - 5 } & $\begin{array}{c}(i=0.04 ; \\
A=0.01)\end{array}$ & $\begin{array}{c}(i=0.1 ; \\
A=0.01)\end{array}$ & $\begin{array}{c}(i=0.04 ; \\
A=0.07)\end{array}$ & $\begin{array}{c}(i=0.1 ; \\
A=0.07)\end{array}$ \\
\hline 25 & 113 & 202 & 16 & 29 \\
\hline 50 & 139 & 228 & 20 & 33 \\
\hline 75 & 165 & 254 & 24 & 36 \\
\hline 100 & 199 & 288 & 28 & 41 \\
\hline 150 & 234 & 323 & 33 & 46 \\
\hline 200 & 302 & 391 & 43 & 56 \\
\hline 250 & 365 & 454 & 52 & 65 \\
\hline 300 & 408 & 497 & 58 & 71 \\
\hline 350 & 419 & 508 & 60 & 73 \\
\hline 400 & 460 & 549 & 66 & 78 \\
\hline 450 & 504 & 592 & 72 & 85 \\
\hline 500 & 542 & 631 & 77 & 90 \\
\hline 550 & 575 & 664 & 82 & 95 \\
\hline 600 & 613 & 702 & 88 & 100 \\
\hline
\end{tabular}

impact, high break growth rate, and low discount rate may save a significant amount of money with the newly proposed model. For example, for the 2-loop network for a typical set of values, the cost benefit is as much as $12.92 \%$.

It is apparent from the large body of literature on pipe deterioration that large quantities of accurate data are required to model the behaviour and deterioration of a water distribution system. To initiate a design based on the procedure proposed in this paper, pipe-break data are required. However, it is not possible to obtain the pipe-break data before installing pipes. Therefore it is obvious that the data pertaining to other systems which have similar characteristics (load, soil, etc.) should be used. When extending an existing water distribution system to cover more service area, the data from the existing network may be useful. Maintenance of records on pipe breaks and repairs by the water distribution utilities will greatly assist economic analyses as presented. In this study, the analysis period is set to 50 years. When optimisation is performed with pipe replacement, the results will be significantly dependent on the analysis period too. A period of 50 years may be a reasonably long period for such analysis as there are a number of scenario changes in like new developments in pipe materials, connection and laying procedures, expectation of service, willingness to pay, etc.

From the results, it is apparent that when the repair and replacement costs are included in optimisation model as demonstrated, this may result in larger diameter pipes. The larger diameter pipes are generally good as they provide more hydraulic reliability. During a pipe-failure scenario, the larger diameter pipes are useful to provide alternate flow paths. However, during normal supply conditions, the larger diameter pipes tend to have low flow velocities which might potentially lead to water

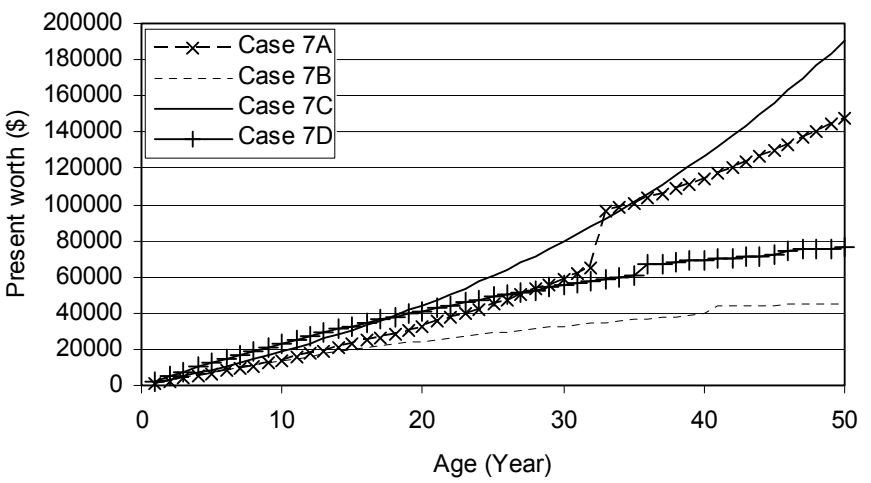

Figure 4

Age and cumulative maintenance cost

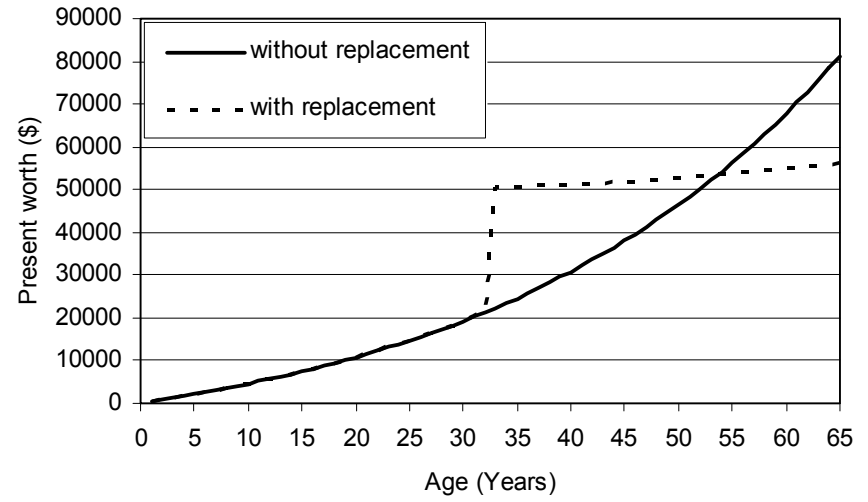

Figure 5

Cumulative maintenance cost for $150 \mathrm{~mm}$ pipe that requires replacement in $33^{\text {rd }}$ year

quality problems. Hence adequate checks should be made on water velocity in pipes before a final design is arrived at. The developed model can further be extended to stage-by-stage construction and rehabilitation of pipes. In this study, a constant Hazen-Williams coefficient is used. However, the value of the Hazen-Williams coefficient decreases with increasing pipe age. This can also be incorporated in the optimisation model. When pumps are involved in the design, an optimisation model with changing roughness values will be more appropriate.

\section{References}

ALPEROVITS E and SHAMIR U (1977) Design of optimal water distribution systems. Water Resour. Res. 13 (6) 885-900.

BALLA MC and LINGIREDDY S (2000) Distributed genetic algorithm model on network of personal computers. J. Comput. Civ. Eng. ASCE 14 (3) 199-205.

BAO Y and MAYS LW (1990) Model for water distribution system reliability. J. Hydraul. Eng. ASCE 116 (9) 1119-1137.

BOCCELLI DL, TRYBY ME, UBER JG, ROSSMAN L A, ZIEROLF ML and POLYCARPOU MM (1998) Optimal scheduling of booster

\begin{tabular}{|c|c|c|c|c|c|c|c|}
\hline \multicolumn{8}{|c|}{$\begin{array}{c}\text { TABLE } 7 \\
\text { Optimal results with pipe replacement option }\end{array}$} \\
\hline Case & $\begin{array}{l}\text { Damage and } \\
\text { other cost } \\
\text { multiplier } D\end{array}$ & $\begin{array}{c}\text { Break growth } \\
\text { rate coeffi- } \\
\text { cient } A(1 / \mathrm{yr})\end{array}$ & $\begin{array}{c}\text { Discount } \\
\text { rate } i \\
(\% / y r)\end{array}$ & $\begin{array}{l}\text { Optimal diameter } \\
\text { set }\end{array}$ & $\begin{array}{c}\text { Pipe(s) and } \\
\text { age of replace- } \\
\text { ment }\end{array}$ & $\begin{array}{l}\text { Initial cost } \\
(1000 \$)\end{array}$ & $\begin{array}{l}\text { Total cost for } \\
50 \text { years } \\
(1000 \$)\end{array}$ \\
\hline $7 \mathrm{~A}$ & 1.5 & 0.07 & 4 & TPQK-QMPM & K-33 & 1142 & 1290.0 \\
\hline $7 \mathrm{~B}$ & 1.5 & 0.07 & 10 & TQQH-PHPN & H-41 & 1109 & 1154.4 \\
\hline $7 \mathrm{C}$ & 2.5 & 0.07 & 4 & TPQM-QMPM & Nil & 1179 & 1370.1 \\
\hline 7D & 2.5 & 0.07 & 10 & SQQG-QKPP & G-36; K-46 & 1102 & 1178.0 \\
\hline
\end{tabular}


disinfection in water distribution systems. J. Water Resour. Plann. Manage. ASCE 124 (2) 99-111.

BOULOS PF and WOOD DJ (1990). Explicit calculation of pipe network systems. J. Hydraul. Eng. ASCE 116 (11) 1329-1344.

CULLINANE MJ, LANSEY KE and MAYS LW (1992). Optimisationavailability-based design of water distribution networks. J. Hydraul. Eng. ASCE 118 (3) 420-441.

CUNHA M and SOUSA J (1999) Water distribution network design optimisation: Simulated annealing approach. J. Water Resour. Plann. Manage. ASCE 125 (4) 215-221.

DANDY GC and ENGELHARDT M (2001) Optimal scheduling of water pipe replacement using genetic algorithms. J. Water Resour. Plann. Manage. ASCE 127 (4) 214-223.

DANDY GC and ENGELHARDT M (2006) Multi-objective trade offs between cost and reliability in the replacement of water mains. J. Water Resour. Plann. Manage. ASCE 132 (2) 79-88.

EUSUFF MM and LANSEY KE (2003) Optimisation of water distribution network design using the shuffled frog leaping algorithm. J. Water Resour. Plann. Manage. ASCE 129 (3) 210-225.

FUJIWARA O and DESILVA AU (1990) Algorithm for reliabilitybased optimal design of water networks. J. Environ. Eng. ASCE 116 (3) $575-587$

FUJIWARA O and TUNG HD (1991) Reliability improvement for water distribution networks through increasing pipe size. Water Resour. Res. 27 (7) 1395-1402.

GOULTER IC (1992) System analysis in water distribution network design: From theory to practice. J. Water Resour. Plann. Manage. ASCE 118 (3) 238-248.

GOULTER I and BOUCHART F (1990) Reliability-constrained pipe network model. J. Hydraul. Eng. ASCE 116 (2) 211-229.

GOULTER IC and COALS AV (1986) Quantitative approaches to reliability assessment in pipe networks. J. Trans. Eng. ASCE 112 (3) 287-301.

GOULTER IC and KAZEMI A (1988) Spatial and temporal groupings of water main pipe breakage in Winnipeg. Can. J. Civ. Eng. 15 91-97.

GOULTER IC, DAVIDSON J and JACOBS P (1993) Predicting watermain breakage rates. J. Water Resour. Plann. Manage. ASCE 119 (4) 419-436.

GUPTA R and BHAVE PR (1994) Reliability analysis of water distribution systems. J. Environ. Eng. ASCE 120 (2) 447-460.

JAYARAM N and SRINIVASAN K (2008) Performance based optimal design and rehabilitation of water distribution networks using life cycle costing. Water Resour. Res. 44, W01417, DOI: 10.1029/2006WR005316.

KAPELAN ZS, SAVIC DA and WALTERS ZA (2003) Multiobjective sampling design for water distribution model calibration. J. Water Resour. Plann. Manage. ASCE 129 (6) 466-479.

KETTLER AJ and GOULTER IC (1983) Reliability consideration in the least cost design of looped water distribution systems. Proc. 1983 Int. Symp. Urban Hydrol. Hydraul. and Sedi. Cont. Univ. of Kentucky, Lexington, KY, USA, 305-312.

KETTLER AJ and GOULTER IC (1985) An analysis of pipe breakage in urban water distribution networks. Can. J. Civ. Eng. 12 286-293.

KLEINER Y and RAJANI B (1999) Using limited data to assess future needs. J. Am. Water Works Assoc. 91 (7) 47-61.

LAI D and SCHAAKE J (1969) Linear Programming and Dynamic Programming Applications to Water Distribution Network Design. Report No. 116, Department of Civil Engineering, Massachusetts Institute of Technology, Cambridge, Massachusetts, USA.

LANSEY KE, SHORBAGY WE, AHMED I, ARAUJO J and HAAN CT (2001) Calibration assessment and data collection for water distribution networks. J. Hydraul. Eng. ASCE 127 (4) 270-279.

LI D AND HAIMES YY (1992a) Optimal maintenance related decision making for deteriorating water distribution systems: 1. Semi-Markovian model for a water main. Water Resour. Res. 28 (4) 1053-1061.
LI D AND HAIMES YY (1992b) Optimal maintenance related decision making for deteriorating water distribution systems: 2. Multilevel decomposition approach. Water Resour. Res. 28 (4) 1063-1070.

LINGIREDDY S AND ORMSBEE LE (2002) Hydraulic network calibration using genetic optimisation. Civ. Eng. Environ. Syst. 19 (1) 13-39.

LINGIREDDY S, ORMSBEE LE and NEELAKANTAN TR (2000) Application of genetic optimisation in maximising hydraulic network redundancy. In: Rollin H Hotchkiss and Michael Glade (eds.) Proc. Joint Conference on Water Resour. Eng. and Water Resour. Plann. Manage (Water Resources 2000 - Building Partnerships). 30 July - 02 August 2 2000, Minneapolis, Minnesota, USA.

LOGANATHAN GV, PARK S and SHERALI HD (2002) Threshold break rate for pipeline replacement in water distribution systems. J. Water Resour. Plann. Manage. ASCE 128 (4) 271-279.

LUONG HT and NAGARUR NN (2005) Optimal maintenance policy and fund allocation in water distribution networks. J. Water Resour. Plann. Manage. ASCE 131 (4) 299-306.

MAIER HR, SIMPSON AR, ZECCHIN AC, FOONG WK, PHANG KY, SEAH HY and TAN CL (2003) Ant colony optimisation for design of water distribution systems. J. Water Resour. Plann. Manage. ASCE 129 (3) 200-209.

MAILHOT A, POULIN A and VILLENEUVE JP (2003) Optimal replacement of water pipes. Water Resour. Res. 39 (5) HWC 2-1 to HWC 2-14.

MALE JW, WALSKI TM and SLUTSKY AH (1990) Analyzing water main replacement policies. J. Water Resour. Plann. Manage. ASCE 116 (3) 362-374.

MALLICK KN, AHMED I, TICKLE KS and LANSEY KE (2002) Determining pipe groupings for water distribution networks. J. Water Resour. Plann. Manage. ASCE 128 (2) 130-139.

MARTIN QW (1990) Linear water-supply pipeline capacity expansion model. J. Hydraul. Eng. ASCE 116 (5) 675-689.

ORMSBEE LE and KESSLER A (1990) Optimal upgrading of hydraulic-network reliability. J. Water Resour. Plann. Manage. ASCE 116 (6) 784-802.

PRASAD TD and PARK N (2004) Multiobjective genetic algorithms for design of water distribution networks. J. Water Resour. Plann. Manage. ASCE 130 (1) 73-82.

PRASAD TD, WALTERS WA and SAVIC DA (2004) Booster disinfection of water supply networks: Multiobjective approach. J. Water Resour. Plann. Manage. ASCE 130 (5) 367-376.

ROSSMAN LA (2000) EPANET 2- User Manual. National Risk Management Research Laboratory, Office of Research and Development, U.S. Environmental Protection Agency, Cincinnati, Ohio, USA.

SAVIC DA and WALTERS GA (1997) Genetic algorithm for least cost design of water distribution networks. J. Water Resour. Plann. Manage. ASCE 123 (2) 66-77.

SHAMIR U and HOWARD CDD (1979) Analytical approach to scheduling pipe replacement. J. Am. Water Works Assoc. 74 (3) 140-147.

SINSKE SA and HL ZIETSMAN (2004) A spatial decision support system for pipe-break susceptibility analysis of municipal water distribution systems. Water SA 30 (1) 71-79. http://www.wrc.org.za/ archives/watersa\%20archive/2004/Jan-04/11.pdf.

SIMPSON AR, DANDY GC and MURPHY LJ (1994) Genetic algorithm compared to other techniques for pipe optimisation. J. Water Resour. Plann. Manage. ASCE 120 (4) 423-443.

SU YC, MAYS LW, DUAN N and LANSEY KE (1987) Reliability-based optimisation model for water distribution systems. J. Hydraul. Eng. ASCE 114 (12) 1539-1556.

TRYBY ME, BOCCELLI DL, UBER JG and ROSSMAN LA (2002) Facility location model for booster disinfection of water supply networks. J. Water Resour. Plann. Manage. ASCE 128 (5) 322-333.

VITKOVSKY JP, SIMPSON AR and LAMBERT MF (2000) Leak detection and calibration using transients and genetic algorithms. J. Water Resour. Plann. Manage. ASCE 126 (4) 262-265.

WALSKI TM and PELLICCIA A (1982) Economic analysis of water main breaks. J. Am. Water Works Assoc. 74 (3) 140-147. 